\title{
Mammalian X-Chromosome Inactivation: An Epigenetics Paradigm
}

\author{
E. Heard, ' J. Chaumeil, O. Masui, and I. Okamoto \\ CNRS UMR218, Curie Institute, 75248 Paris Cedex 05, France
}

In mammals, dosage compensation for X-linked gene products between XX females and XY males is achieved through the transcriptional silencing of one of the two $X$ chromosomes in the developing female embryo (Lyon 1961). This process of X-chromosome inactivation affects more than 1000 genes and is one of the most striking examples of long-range, monoallelic gene silencing in mammals. The choice of which X chromosome is inactivated is usually random in placental mammals, and the inactive state is then stably inherited, giving rise to adults that are mosaics for two cell types expressing one or the other X chromosome. However, in marsupials and during early embryogenesis of some placental mammals such as rodents, only the paternal X chromosome is inactivated because of a parent-specific imprint. In mice, this imprinted form of X-inactivation is subsequently reversed in cells of the embryo proper and random inactivation of either the paternally or maternally derived $\mathrm{X}$ chromosome occurs. Random X-inactivation also occurs when female embryonic stem (ES) cells are differentiated in vitro, thus providing a useful model system for mechanistic studies. Mechanistically, X-inactivation is usually described as being a multistep process, consisting of initiation from a unique region on the $\mathrm{X}$ chromosome, the $\mathrm{X}$ inactivation center (Xic), followed by spread of inactivation over the $\mathrm{X}$ chromosome, and then maintenance of the inactive state through subsequent cell divisions. Initiation normally can occur only during a restricted developmental time window and is thought to involve the sensing of how many $\mathrm{X}$ chromosomes are present, the choice of $\mathrm{X}$ chromosome to inactivate, and the triggering of the silencing process itself. Spreading involves a cis-acting RNA molecule (Xist), but the factors that this RNA interacts with to mediate silencing and the regions of the $\mathrm{X}$ chromosome that it targets remain poorly understood. Maintenance appears to be independent of Xic function and to rely on a combination of epigenetic marks. Although the distinction of these three steps in X-inactivation facilitates our description of this process, they are in fact inextricably linked, as will become apparent below.

\footnotetext{
"Corresponding author: Mammalian Developmental Epigenetics Group, CNRS UMR218, Curie Institute, 26 rue d'Ulm, 75248 Paris Cedex 05, France. E-mail: Edith.Heard@curie.fr.
}

In this paper, we discuss a number of questions raised by $\mathrm{X}$-inactivation that may also be relevant to other epigenetic processes. How does the inactivation of an entire $\mathrm{X}$ chromosome take place while its homolog, present in the same nucleus, remains genetically active? What are the epigenetic mark(s) that impose nonrandom X-inactivation in some species? What constitutes the cellular memory, whereby the inactive state is stably maintained, not only throughout the cell cycle, including disruptive $\mathrm{S}$ phase and during mitosis, but for hundreds of cell divisions during the lifetime of an organism? What are the epigenetic marks that underlie this cellular memory and how are they erased at the appropriate developmental times? Finally, could some aspects of the differential treatment of two genetically identical chromosomes be explained through specific nuclear localization?

\section{Initiation: Defining the X-Inactivation Center}

The key locus underlying the initial differential treatment of two X chromosomes is the Xic, which is involved in determining how many $\mathrm{X}$ chromosomes are present in a cell (counting) and which $\mathrm{X}$ chromosome will be inactivated (choice). Cells must register the presence of at least two Xics for X-inactivation to occur (Rastan 1983; Rastan and Robertson 1985) and only a single X chromosome will remain active in a diploid cell, all supernumerary $\mathrm{X}$ chromosomes being inactivated. The Xic is also the site from which inactivation spreads across the $\mathrm{X}$ chromosome in cis, or even across an autosome, in X-autosome translocations. Cytogenetic studies on such chromosomal rearrangements and deletions enabled the Xic region to be narrowed down over the years to $\sim 1 \mathrm{Mbp}$ of sequence on the human X (Fig. 1) (see Heard and Avner 1994). The corresponding syntenic region on the mouse $X$ is approximately half this size (Chureau et al. 2002). Within this candidate region, the discovery of a remarkable gene, Xist (X-inactive-specific-transcript), in 1990 provided the first molecular insight into how inactivation is initiated (Brown et al. 1991). Xist is expressed exclusively from the inactive $\mathrm{X}$ chromosome, producing a 17,000-nucleotide-long, untranslated RNA that coats the $\mathrm{X}$ chromosome from which it is produced in cis (Brown et al. 1992; Clemson et al. 1998). Xist RNA is essential for the initiation and spread of $\mathrm{X}$-inactivation in cis (Penny et al. 1996; Marahrens et al. 1997; Wutz and 


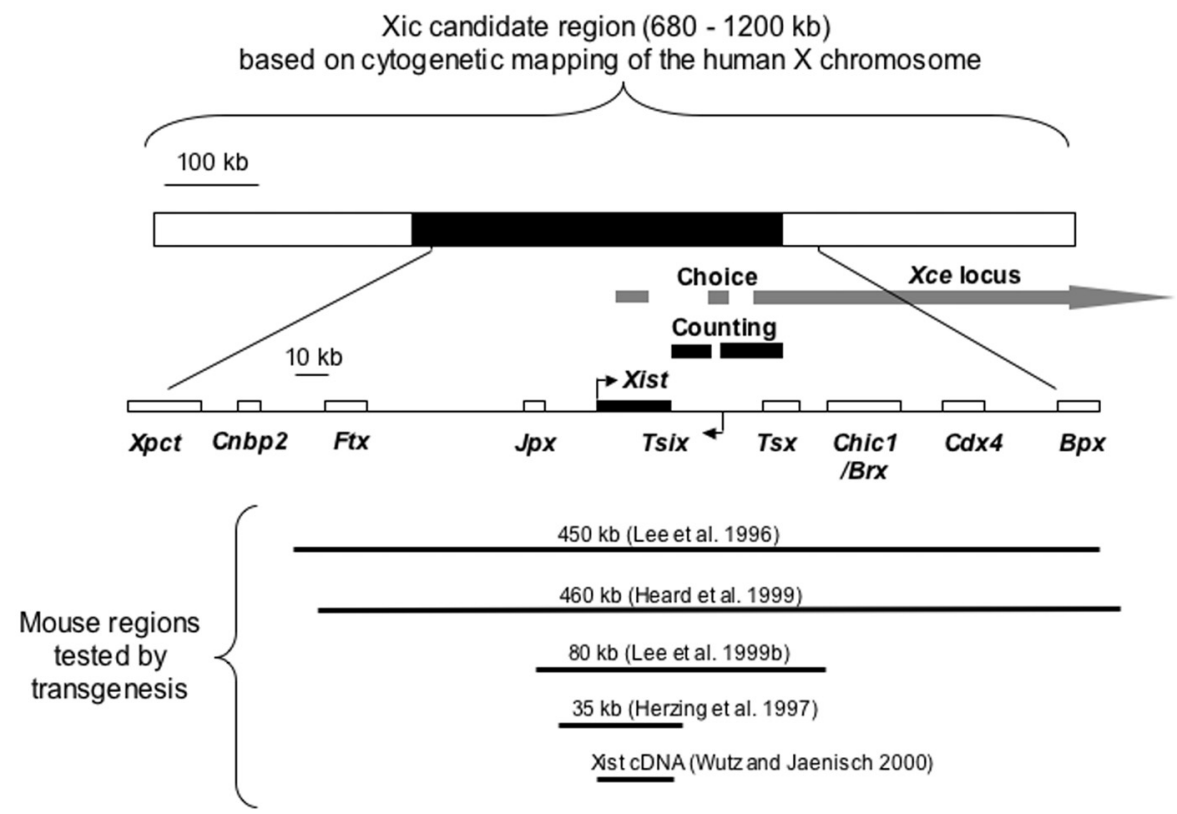

Figure 1. The candidate region for the X-inactivation center. Based on the candidate region defined by cytogenetic mapping of the human XIC region (above), the syntenic mouse region is shown (below). Elements defined to be involved in counting and choice by targeted deletion analysis or genetic mapping (Xce locus) are shown (for review, see Clerc and Avner 2003). Below the map of the murine Xic region, the extents of the mouse transgenes tested for Xic function are shown.

Jaenisch 2000), yet it is not involved in the counting function of the Xic (Penny et al. 1996). A complex combination of antisense transcription to Xist (in the form of Tsix) and cis-regulatory sequences located in the region $3^{\prime}$ to $X i s t$ appear to be involved in the choice and counting functions of the Xic (Fig. 1) (for reviews, see Boumil and Lee 2001; Clerc and Avner 2003). Several studies involving transgenesis, a stringent test for assessing the sequences that are not only necessary, but sufficient, for the function of a locus, have been performed for the Xic with the aim of defining the minimal region sufficient for Xic function at an ectopic (autosomal) site (Fig. 1) (Heard et al. 1996, 1999; Lee et al. 1996, 1999b; Herzing et al. 1997). In transgenic ES cells and mice, such transgenes are able to act as ectopic Xics (when they included the Xist gene); however, they can only do so when present as multicopy arrays. Indeed, single-copy Xist transgenes, up to $460 \mathrm{~kb}$ long (covering $130 \mathrm{~kb}$ of sequence $5^{\prime}$ and $300 \mathrm{~kb}$ of sequence 3 ' to Xist) are unable to induce Xist RNA coating in cis or even to trigger inactivation of the endogenous $\mathrm{X}$ chromosome (counting) (Heard et al. 1999). Critical elements for autonomous Xic function must therefore still be lacking from these large single-copy transgenes, and multicopy arrays must compensate for this lack in some way. Indeed, comparison with the cytogenetic definition of the Xic region in humans (Fig. 1) suggests that missing sequences are likely to lie in the $5^{\prime}$ region of Xist.

These transgenes may be lacking sufficient numbers of repeat elements, or "way stations," as first proposed by Riggs (Riggs et al. 1985), necessary for the nucleation and propagation of the Xist RNA-mediated signal along the chromosome. Mary Lyon has proposed L1 repeat el- ements (LINEs) as possible way stations (Lyon 1998), given their enrichment on the $\mathrm{X}$ chromosome relative to autosomes. Strikingly, LINE density in the region covered by the Xist transgenes (Fig. 1) is not particularly high (Chureau et al. 2002), which would correlate well with a need for multiple copies of this region to compensate for this relative lack in LINEs. The overexpression of Xist can, however, compensate for whatever sequences might be lacking at ectopic sites, to produce cis-inactivation (Wutz and Jaenisch 2000). Thus, an alternative, but not mutually exclusive, possibility is that long-range elements that enhance Xist expression, or buffer it from position effects, are lacking in the single-copy genomic Xist transgenes. Consistent with this, recent studies have shown that unique characteristics define a region spanning hundreds of kilobases upstream of Xist. These include a $100-\mathrm{kb}$ stretch of chromatin that is histone H4 hyperacetylated in XX but not XY cells (O'Neill et al. 1999), a >200-kb domain that is constitutively enriched for H3 Lys-9 dimethylation (Heard et al. 2001; Rougeulle et al. 2004), and a series of noncoding RNAs that are produced from this region (Chureau et al. 2002). The absence of at least part of the Xist upstream region in the genomic transgenes tested so far, especially the large H3 Lys-9 methylation domain, could explain the lack of singlecopy Xic function (Heard et al. 2001; Rougeulle et al. 2004). Given that the region involved in counting, $3^{\prime}$ to Xist (Clerc and Avner 1998), lies intact within the large genomic transgenes tested so far (Heard et al. 1999), the complete absence of X-inactivation in these single-copy transgene lines could be related to an incorrect positioning of these transgenes in the nucleus, which would not 
permit their detection as a supplementary Xic and the initiation of inactivation of the endogenous $\mathrm{X}$ chromosome (see final section).

\section{Spreading the Inactive State via Xist RNA}

The earliest known event in the $\mathrm{X}$-inactivation process, both in embryos and in differentiating ES cells (Fig. 2 and Fig. 4, below), consists of coating of the $\mathrm{X}$ chromosome by Xist RNA, which is rapidly followed by gene silencing along the length of the chromosome (Kay et al. 1993; Panning et al. 1997; Sheardown et al. 1997; Wutz and Jaenisch 2000). Xist RNA-induced transcriptional shutdown can occur only during an early developmental time window (Wutz and Jaenisch 2000). However, how this is achieved and the identity of the key protein or nucleic acid partners of Xist that are involved remain to be elucidated. In order to gain insight into Xist's functions, we set out to characterize early chromatin changes, such as covalent modifications of histones, on the $\mathrm{X}$ chromosome. Histone modifications, including acetylation, methylation, phosphorylation, and ubiquitination, represent an important means of regulating gene expression (Jenuwein and Allis 2001; Zhang and Reinberg 2001) and may even form a "histone code," through the binding of chromatinassociated proteins (Strahl and Allis 2000; Turner 2000). The inactive $\mathrm{X}$ chromosome is characterized by a number of histone modifications (see Fig. 3) (Jeppeson and Turner 1993; Boggs et al. 1996, 2002; Keohane et al. 1996), some of which are common to other regions of heterochromatin. We have shown that during female ES cell differentiation (Fig. 2), specific patterns of histone modifications, including H3 Lys-9 dimethylation and H3 Lys4 hypomethylation, appear on the $\mathrm{X}$ chromosome soon after Xist RNA coating (Heard et al. 2001; Chaumeil et al. 2002). More recently, H3 Lys-27 trimethylation (Plath

A.

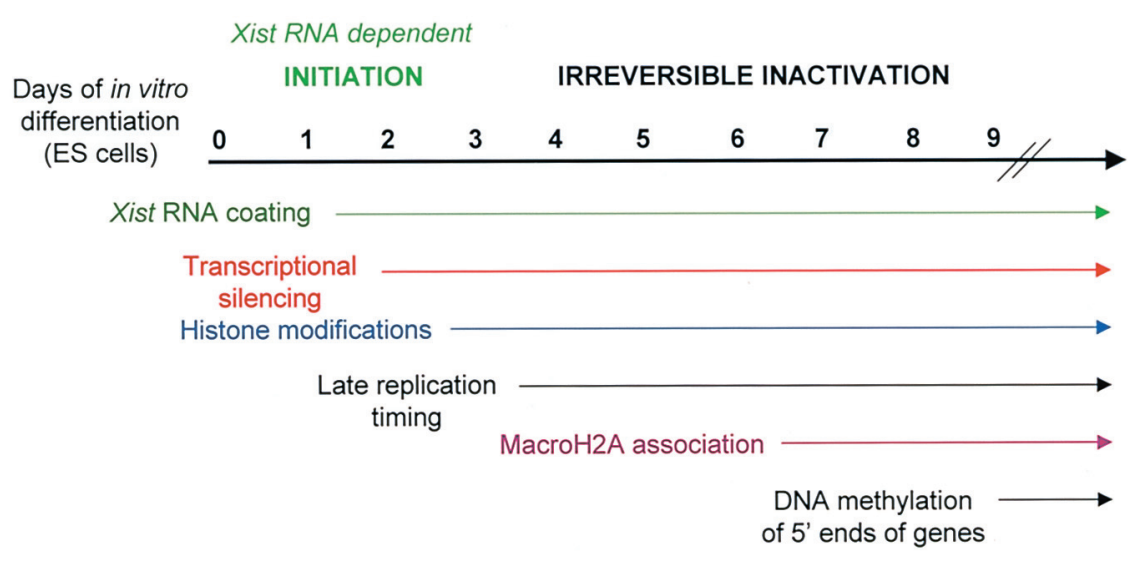

B.

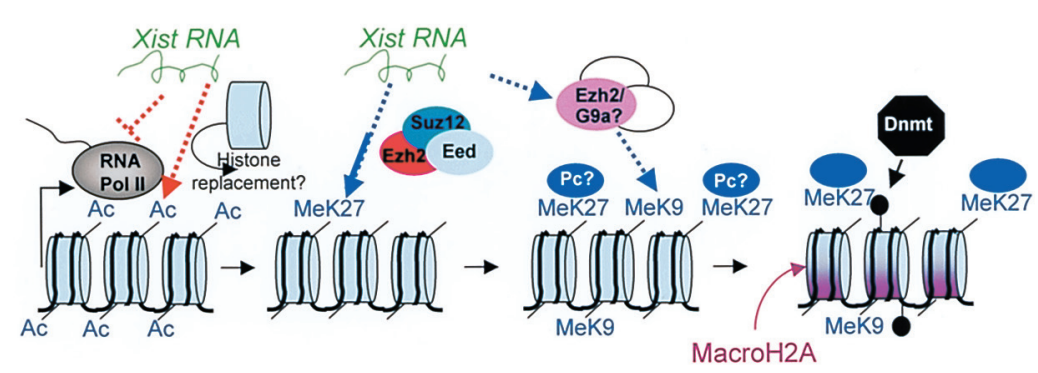

Figure 2. Kinetics of X-inactivation in differentiating ES cells. $(A)$ The time of onset of different events during the onset of X-inactivation is shown, deduced thanks to numerous studies (Keohane et al. 1996; Penny et al. 1996; Panning et al. 1997; Sheardown et al. 1997; Wutz and Jaenisch 2000; Heard et al. 2001; Chaumeil et al. 2002; Plath et al. 2003; Silva et al. 2003; Kohlmaier et al. 2004). (B) Proposed mechanisms underlying X-inactivation. Xist RNA may first act by directly interfering with transcription initiation and/or elongation on the X chromosome (J. Chaumeil and E. Heard, unpubl.; for details, see text). In order to achieve the loss of euchromatic histone modifications such as H3 Lys-4 methylation (and given that no histone demethylases have so far been identified), Xist RNA may promote histone replacement or histone proteolysis. Finally, Xist RNA can recruit (either directly or via intermediate proteins) PRC2 complex polycomb group proteins (Ezh2/EnxI and Eed), which enable methylation of H3 Lys-27 (Plath et al. 2003; Silva et al. 2003; Kohlmaier et al. 2004); methylation of H3 Lys-9 may be mediated by Ezh2 or another histone methyltransferase such as G9a (Heard et al. 2001; Rougeulle et al. 2004). Although no PRC1 complex proteins have so far been found associated with the Xi, methylated H3 Lys-27 is likely to serve as a signal for the recruitment of the PRC1 complex, perhaps via a homolog of the Polycomb (Pc) protein itself (Fischle et al. 2003; Min et al. 2003), thus facilitating the maintenance of transcriptional silence. The histone variant, macroH2A, is Xist RNA-dependent, although it is not clear whether this is a direct recruitment or dependent on other changes induced by Xist (hence no arrow linking the two is shown). The mechanism by which DNA methyltransferases are recruited to the promoters of X-linked gene on the Xi remains unclear, but may be via the histone modifications or polycomb group proteins already bound. Dashed arrows: hypothetical links between Xist and various potential factors such as polycomb group proteins. 

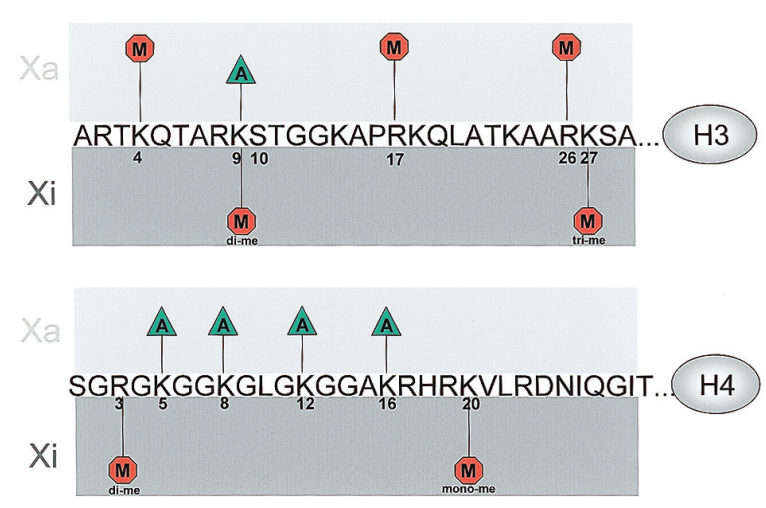

Figure 3. Histone modification patterns on the active and inactive $\mathrm{X}$ chromosomes. Histone modifications characterizing the inactive $\mathrm{X}$ chromosome and their equivalent state on the active X chromosome are shown (based on Jeppeson and Turner 1993; Boggs et al. 1996, 2002; Keohane et al. 1996; Heard et al. 2001; Chaumeil et al. 2002; Chadwick and Willard 2003; Plath et al. 2003; Silva et al. 2003; Kohlmeier et al. 2004).

et al. 2003; Silva et al. 2003) and H4 Lys-20 monomethylation (Kohlmaier et al. 2004) have been shown to appear within a similar time window. The early time of appearance of these histone changes and their presence on the $\mathrm{Xi}$ in somatic cells suggested that they could be involved in the transcriptional silencing process, or in its maintenance, or both. Furthermore, their appearance immediately following Xist RNA coating suggested that the Xist transcript might actually target histone-modifying enzymes to the $\mathrm{X}$ chromosome. Indeed, members of the Polycomb group PRC2 complex, Eed and Ezh2/Enx1, the latter being a histone methyltransferase capable of trimethylating H3 Lys-27 (Kuzmichev et al. 2002), were found to be recruited to the inactive X chromosome in what appears to be a Xist RNA-dependent fashion (Plath et al. 2003; Kohlmaier et al. 2004). The dimethylation of H3 Lys-9 on the Xi may not be Xist RNA-dependent and may be mediated by a different HMTase and/or complex, as its kinetics of appearance (Okamoto et al. 2004) and chromosomal distribution (Rougeulle et al. 2004) are different to H3 trimethyl Lys27 (Fig. 2B).

Although Xist's role was considered to be restricted to transcriptional silencing up until recently, the recruitment of the PRC2 complex and H3 Lys-27 methylation by Xist does not seem to be involved in silencing (Kohlmaier et al. 2004), but rather to the early maintenance of the inactive state (Plath et al. 2003; Silva et al. 2003). A maintenance role for PRC2 complex is also supported by genetic evidence in Eed mutant embryos (Wang et al. 2001; Silva et al. 2003). Xist RNA may therefore have parallel roles, one in transcriptional silencing and the other in recruiting marks involved in early maintenance. Consistent with this, recent data from our laboratory, using immunofluorescence and green fluorescent protein (GFP)-tagged protein analyses, has shown that the exclusion of RNA polymerase II and associated transcription factors from the X chromosome occurs concurrently with Xist RNA coating and before histone modifications such as H3 Lys-27 and
Lys-9 methylation (Fig. 2) (J. Chaumeil and E. Heard, unpubl.). Clearly, identification of the protein complexes involved in the various roles of Xist RNA, as well as the chromosomal regions that are targeted by Xist and its partners, represent critical questions for the future.

\section{MAINTENANCE: EPIGENETIC MARKS AND CELLULAR MEMORY}

Once silencing has been established on the X chromosome, it has to be maintained during the cell cycle and throughout the multiple cell divisions that occur during the lifetime of an organism. The inactive state of genes on the $\mathrm{Xi}$ is highly stable in somatic cells, with sporadic reactivation frequencies similar to mutation rates in wildtype cells $\left(<10^{-8}\right)$. Furthermore, experimental reactivation of the entire chromosome in somatic cells has never been observed. What are the epigenetic marks responsible for this remarkable stability? Current thinking is that there are several layers of epigenetic modifications that could be involved in locking in the inactive state in a synergistic fashion (Csankovszki et al. 2001). Histone modifications, some of which may be recruited via Xist RNA as described above, represent one set of candidates. Such modifications are thought to participate in transcriptional repression on the one hand (Strahl and Allis 2000) and could be mitotically heritable chromatin marks on the other (Turner 2000). In order to represent true epigenetic marks, these modifications must also be heritable during DNA replication when nucleosomes are distributed randomly between the daughter strands, as well as being resistant to histone replacement processes that can occur at other times during the cell cycle (Henikoff et al. 2004; see Nakatani et al., this volume). Although many of these histone modifications appear to be detectable on the $\mathrm{X}$ chromosome at all times by immunofluorescence and by chromatin immunoprecipitation (ChIP), clearly this type of analysis cannot provide the resolution or dynamic vision necessary to address the issue of heritability. The purification of histones specifically associated with the $\mathrm{Xi}$ during different phases of the cell cycle, as well as the analysis of histone exchange rates associated with the $\mathrm{Xi}$ in living cells, should provide insights into this.

The polycomb group proteins are excellent candidates for participating in the cellular memory of inactivity, based on genetic studies in Drosophila showing their role in heritability of silent states (for recent review, see Cao and Zhang 2004). In the case of mammalian X-inactivation, members of the PRC2 complex and H3 Lys-27 methylation are recruited to the $\mathrm{X}$, potentially via Xist, during the early stages of X-inactivation, as described above (Fig. 2B). However, recruitment to the the inactive $\mathrm{X}$ of PRC1 complex members and, in particular, of the Pc protein, which in Drosophila can bind H3 trimethyl K27, has not been reported so far, although it seems highly likely that at least some mouse Pc homologs (Tajul-Arifin et al. 2003) will indeed associate with the Xi. Our understanding of the role of polycomb group proteins in maintaining the inactive state of the $\mathrm{X}$ chromosome is still very rudimentary. Furthermore, significant differences 
have been found in the degree to which the maintenance of the $\mathrm{Xi}$ is dependent on $\mathrm{PRC} 2$ between extraembryonic and embryonic lineages (Wang et al. 2001). Biochemical and functional studies will provide important insights into this, although the situation is likely to be complicated, given the dynamic composition of these complexes and their functional redundancy in mammalian cells.

Aside from the histone modifications and polycomb group proteins, a number of other features that distinguish the inactive $\mathrm{X}$ chromosome from its active counterpart could be involved in maintenance of the inactive state. One such characteristic is asynchronous replication timing of the inactive $\mathrm{X}$ chromosome. Replication of the $\mathrm{Xi}$ at the very beginning or the very end of S phase may provide a temporal segregation of the two $\mathrm{X}$ chromosomes and minimize the exposure of the Xi to transcription factors, thus facilitating the maintenance of transcriptional silence. Indeed, asynchronous replication timing is one of the most conserved features of the inactive $\mathrm{X}$ chromosome across mammalian taxa (for review, see Heard et al. 1997). Its appearance correlates well with the transition period from the Xist RNA-dependent to Xist RNA-independent, irreversible silencing (Fig. 2A). Late replication of the Xi appears to occur after the changes in histone modifications described so far (Chaumeil et al. 2002), suggesting that the altered chromatin structure of the Xi may be necessary for replication to shift, although this has yet to be formally tested. The inactive $\mathrm{X}$ is also enriched in a histone H2A variant, macro-H2A.1 (Costanzi and Pehrson 1998). In vitro studies have shown that macro-H2A.1 can interfere with transcription factor binding and SWI/SNF nucleosome remodeling (Angelov et al. 2003), although its exact role in $\mathrm{X}$-inactivation is unclear. Its relatively late appearance on the Xi during inactivation (Fig. 2A) suggests that it is a maintenance, as opposed to an initiation, mark, although intriguingly it seems to be dependent on Xist RNA coating (Csankovszki et al. 1999). Another apparently late modification of the inactive $\mathrm{X}$ chromosome is DNA (cytosine) methylation of $\mathrm{CpG}$ islands at the $5^{\prime}$ ends of $\mathrm{Xi}$ linked genes. The recruitment of methyl binding proteins involved in silencing and the heritability of the methyl mark during DNA replication (thanks to DNA methyltransferases that can recognize hemimethylated DNA) makes DNA methylation probably the most "dependable" of epigenetic marks known to date. Analysis of Dnmt1 $1^{-1}$ mutant embryos has shown that methylation is indeed required for stable maintenance of gene silencing on the $\mathrm{Xi}$ in the embryonic lineage (Sado et al. 2000). In extraembryonic lineages on the other hand, the 5' ends of X-linked genes do not appear to be hypermethylated. Although this correlates with higher rates of sporadic reactivation of Xlinked genes (Kratzer et al. 1983), it seems that the maintenance of the inactive state, at least in some extraembryonic tissues such as the visceral endoderm, can tolerate extensive demethylation in vivo (Sado et al. 2000). This could be consistent with an important role for other epigenetic marks, such as the polycomb group proteins, in extraembryonic lineages (Wang et al. 2001). In marsupials, on the other hand, $\mathrm{CpG}$ islands of genes are not methylated on the inactive $\mathrm{X}$ chromosome in any of the lineages
(Kaslow and Migeon 1987). Perhaps as a consequence, higher frequencies of sporadic reactivation of X-linked genes are found in marsupials compared to placental mammals, although the rate of reactivation varies considerably between genes (for review, see Heard et al. 1997). Thus the relative roles of different epigenetic marks in maintaining the inactive state of the $\mathrm{X}$ chromosome seem to vary considerably across species, and even between cell lineages and different genes within the same species.

In order to assess the relative importance of different epigenetic marks in maintaining the inactive state of the $\mathrm{X}$ chromosome, studies aimed at preventing or reversing them have been performed. Removal of any one epigenetic mark (e.g., histone H3 Lys-27 methylation [using Eed mutant mice; Silva et al. 2003], hypoacetylation [following treatment with histone deacetylase inhibitors such as TSA], or DNA methylation [following 5-aza-cytosine treatment or in DNA methyltransferase Dnmt1 mutant cells]) can lead to a slightly higher sporadic reactivation rate of X-linked genes (Csankovszki et al. 2001). On the other hand, the combined absence of Xist RNA coating (which also leads to depletion of macroH2A.1 on the Xi), DNA methylation, and histone hypoacetylation in somatic cells does lead to a significantly increased rate of sporadic gene reactivation on the inactive $\mathrm{X}$, implying that it is the multiplicity of epigenetic marks that ensures stability (Csankovszki et al. 2001). Nevertheless, even under these conditions, global reactivation of the $\mathrm{X}$ chromosome is never seen, although if it did occur it would be likely to induce rapid cell death owing to overexpression of X-linked genes. In fact, $\mathrm{X}$-chromosome-wide reactivation normally takes place only during development (see below), in the inner cell mass of the blastocyst (4.5-5.5 $\mathrm{dpc})$, and later in the primordial germ cells of the germ line ( 12.5 dpc) (Fig. 4).

\section{DEVELOPMENTAL DYNAMICS AND DIVERGENCE OF IMPRINTED AND RANDOM X-INACTIVATION}

\section{Evolutionary Considerations}

In marsupials (Cooper et al. 1971; Sharman 1971) and in the extraembryonic tissues of some placental mammals, such as rodents (Takagi and Sasaki 1975; West et al. 1977) and cattle (Xue et al. 2002), X-inactivation is nonrandom, with exclusive inactivation of the paternal $\mathrm{X}$ chromosome (Xp). Based on phylogenetic analysis it has been suggested that imprinted $\mathrm{X}$-inactivation may represent the ancestral state of this process, arising $>130$ million years ago in metatheria (Richardson et al. 1971). In this scenario, random X-inactivation would have evolved subsequently, only in placental mammals. Indeed, there are clear selective advantages for random X-inactivation, as the cellular mosaicism engendered allows survival of females even in the presence of deleterious X-linked gene mutations. In rodents, it has been proposed that the imprinted form of X-inactivation that occurs in the early embryo could represent a vestige of the ancestral form. In other placental mammals such as humans, however, this form appears to have been lost completely. Although the 


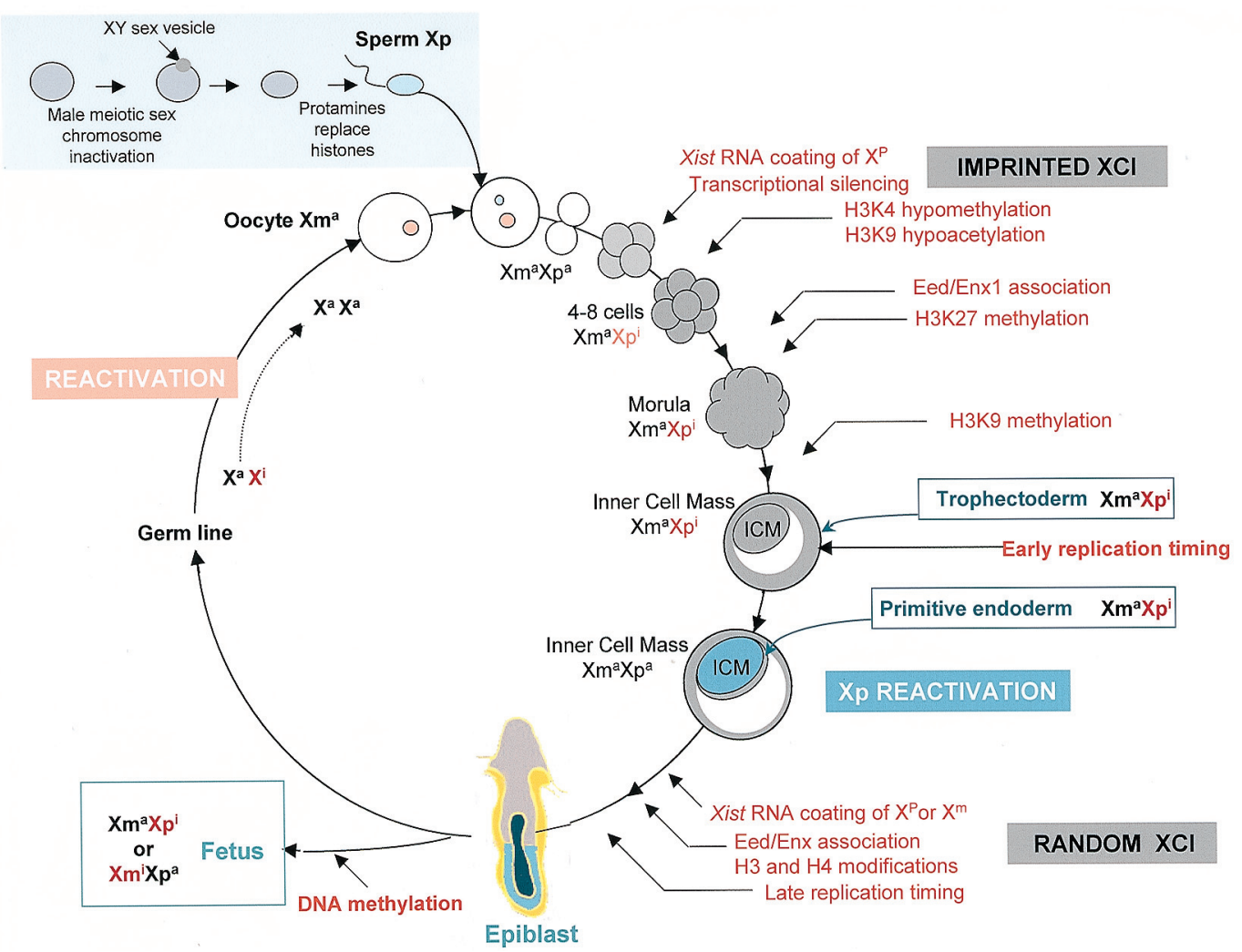

Figure 4. The $\mathrm{X}$-inactivation cycle in the mouse. The $\mathrm{X}$-inactivation events during female mouse development are summarized. Most evidence suggests that the $\mathrm{Xp}$ is initially active $\left(\mathrm{X}^{\mathrm{a}}\right)$ in the early female embryo, like its maternal counterpart, although it has been proposed to arrive in a preinactivated state because of its passage through the male germ line (see text). Inactivation of the Xp chromosome initiates following the accumulation of Xist RNA from the four-cell stage onward (Huynh and Lee 2003; Okamoto et al. 2004). Xp-inactivation is maintained in the trophectoderm $(3.5 \mathrm{dpc})$ and primitive endoderm $(4.5 \mathrm{dpc})$, both of which go on to form extraembryonic tissues. Asynchronous replication timing of the Xi accompanies this transition. The Xp is reactivated in cells of the inner cell mass (ICM) of the blastocyst (Mak et al. 2004; Okamoto et al. 2004). Random X-inactivation of the paternal or maternal X chromosome then takes place at around $5.5 \mathrm{dpc}$, in cells derived from the ICM that go on to form the embryo proper, presumably following the kinetics shown based on studies in differentiating ES cells, which are derived from the ICM (see Fig. 2). The Xi is reactivated in the female germ line just prior to the onset of meiosis.

sequence of evolutionary steps described above is very appealing in its simplicity, an alternative hypothesis has to be considered, which is that imprinting of the X-inactivation process may have been imposed more than once during evolution, under selective pressures specific to different mammals. Indeed, despite the apparent similarities in imprinted $\mathrm{X}$-inactivation between marsupials and the extraembryonic tissues of rodents, these mammals show fundamental differences in their early development and extraembryonic tissue formation (Selwood 2001), in their sexual differentiation and determination strategies (Watson et al. 2000), and possibly even in their regulation of X-inactivation: in fact, no homolog of the Xist gene has been identified in marsupials to date (Graves and Westerman 2002). The selection forces acting on X-linked gene expression during the development of different mammals are thus likely to be diverse and imprinted $\mathrm{X}$-inactivation may have evolved independently in marsupials and eutherians (Olhsson et al. 2001). The strategies used to achieve imprinted $\mathrm{X}$-inactivation may therefore be very different between the two taxa.
Whatever the reasons for the evolution of imprinted Xinactivation, an obvious question is why it always appears to be the paternal $\mathrm{X}$ that is inactivated. Although an imprinted mark on the maternal $\mathrm{X}$ chromosome preventing it from inactivation clearly exists, whether there is an imprint on the paternal $\mathrm{X}$ chromosome, predisposing it to be inactivated, is less clear (Jamieson et al. 1997). One hypothesis posits that preferential paternal X-inactivation could have evolved by exploiting a form of inactivation observed in male germ cells of many species (male meiotic sex chromosome inactivation or MMSI), which involves the transient inactivation of the Xp and Y chromosomes (Lifschytz and Lindsley 1972). The MMSI process presumably prevents deleterious, illegitimate recombination events between the unpaired regions of the sex chromosomes and other chromosomes during meiosis (Jablonka and Lamb 1988). If this meiotically induced inactivity of the $\mathrm{Xp}$ was somehow transmitted to the female zygote, it may have been selected for because of the dosage compensation it could provide in early XX embryos (for reviews, see Jamieson et al. 1997; Huynh and 
Lee 2003). However, as discussed below, there is as yet little evidence to support this in rodents, and the question remains open in marsupials. Ultimately, our comprehension of the possible causes of imprinted X-inactivation, and of the evolutionary similarities or differences between marsupial and rodent imprinted X-inactivation, can come only from a knowledge of the epigenetic marks and the early events underlying this process in different species.

\section{The Nature of the Imprint(s) Underlying Imprinted $\mathrm{X}$-Inactivation in Mice}

Conceptually, imprinted Xp-inactivation could be achieved in two ways: Either the paternal X chromosome is predisposed to inactivate or the maternal $\mathrm{X}$ chromosome $(\mathrm{Xm})$ is marked to remain active (Lyon and Rastan 1984). The failure to develop extraembryonic tissues and the early death of mouse embryos carrying two Xm chromosomes suggests that there is initially a powerful maternal mark that prevents the Xm from being inactivated during early embryogenesis (Goto and Takagi 1998, 1999). On the other hand, mice with an XpO genotype are fully viable and normal (showing only a slight growth retardation in early development) (Burgoyne and Biggers 1976), which demonstrates that the paternal X is not irrevocably destined to inactivate during early development. Direct evidence that there is a maternal mark, which prevents the $\mathrm{Xm}$ from being inactivated, has come from an elegant study on embryos that were derived by combining maternal genomes from a fully grown (fg) oocyte and from an early nongrowing (ng) oocyte (Tada et al. 2000). In such embryos, the $\mathrm{X}$ chromosome derived from the ng oocyte was found to be inactivated in extraembryonic lineages, consistent with acquisition of an Xm mark on the fg X chromosome during oocyte maturation. However, what this mark is and where it lies have remained elusive. Analysis of mice carrying germ-line mutations of genes that encode factors potentially responsible for the epigenetic mark (such as DNA and histone methyltransferases) will be crucial for our understanding of its nature. In terms of its location, the imprinted mark is likely to act at the level of Xist, as the maternally inherited Xist gene is silent in the zygote and during early cleavage stages (Kay et al. 1994) and cannot be expressed, even in the face of strong selective pressure, such as when a paternally inherited Xist deletion prevents the Xp from undergoing inactivation (Marahrens et al. 1997). DNA methylation of Xist's 5' end has been found in oocytes (Ariel et al. 1995; Zuccotti and Monk 1995), but this methylation is mosaic (Goto and Monk 1998; McDonald et al. 1998). The antisense Tsix transcript has also been proposed as a candidate for the maternal imprint, given its repressive effect on Xist RNA accumulation in differentiating ES cells and blastocysts (Lee et al. 1999a; Lee 2000; Stavropoulos et al. 2001). However, Tsix is not normally expressed in cleavage-stage embryos at the time when the maternally inherited Xist allele is repressed (Debrand et al. 1999; I. Okamoto and E. Heard, unpubl.). Furthermore, no differential DNA methylation of the Tsix $5^{\prime}$ region has so far been identified during early development (Prissette et al. 2001). Deletions of the promoter region of Tsix do, nevertheless, lead to aberrant maternal Xist expression and embryonic lethality, presumably because of Xm-inactivation (Lee 2000; Sado et al. 2001). This could mean that the Tsix promoter region contains DNA elements responsible for the maternal silencing of Xist. However, Tsix mutants have so far been examined only at embryonic stages (blastocyst and beyond) where the maternal repressive mark would normally no longer be present (Lee 2000; Sado et al. 2001).

Although an imprinted mark on the maternal X chromosome preventing it from inactivation clearly exists, whether there is an imprint on the paternal $\mathrm{X}$ chromosome, predisposing it to be inactivated, is less clear. Recent work from our laboratory, as well as that of J. Lee (Huynh and Lee 2003; Okamoto et al. 2004), has shown that the $\mathrm{Xp}$ chromosome is, in fact, inactive in cleavagestage embryos. Huynh and Lee have interpreted this finding as meaning that the Xp actually arrives in the zygote in a "preinactivated" state thanks to its passage through the male germ line, where MMSI takes place (Huynh and Lee 2003). Although, in an evolutionary sense, this interpretation may be very satisfying, several lines of evidence challenge it, at least in the mouse. First, using three different single-cell assays for transcriptional activity (the presence of RNA Polymerase II on the Xp, RNA fluorescence in situ hybridization [FISH] to detect nascent transcripts of X-linked genes, and Cot-1 repeatspecific RNA FISH), we have found that the $\mathrm{Xp}$ is, in fact, active in the two-cell embryo and becomes inactivated only from the four-cell stage onward (Fig. 4) following Xist RNA coating (Okamoto et al. 2004; I. Okamoto and E. Heard, in prep.). A second line of evidence is that the MMSI-induced inactivity of the Xp appears to be reversed prior to fertilization, as several Xlinked genes are found to be reexpressed in postmeiotic spermatids (Hendriksen et al. 1995). Third, unlike imprinted X-inactivation, which is dependent on Xist, MMSI is Xist-independent (McCarrey et al. 2002; Turner et al. 2002) and occurs through a very different process (Fernandez-Capetillo et al. 2003). Finally, we have recently found that paternally transmitted autosomal Xist transgenes, which do not show any signs of MMSI in the male germ line, are still able to induce imprinted inactivation in cis in the early mouse embryo (I. Okamoto et al., in prep.). Based on these observations, we conclude that imprinted X-inactivation in rodents does not appear to depend on Xp-preinactivation as a result of MMSI in the male germ line. Rather, it is allele-specific Xist expression that appears to be the critical determinant for imprinted Xp-inactivation. The region $5^{\prime}$ to Xist becomes hypomethylated during spermatogenesis (Norris et al. 1994) and, following fertilization, the paternally inherited Xist allele is expressed, like other genes, at the time of zygotic gene activation (Fig. 5). In the face of the imprinted silence of the maternal Xist allele, paternal Xist RNA accumulation leads to the rapid silencing of the Xp. Indeed, consistent with Xist being the trigger for imprinted Xp-inactivation, silencing of $\mathrm{X}$-linked genes appears to occur 


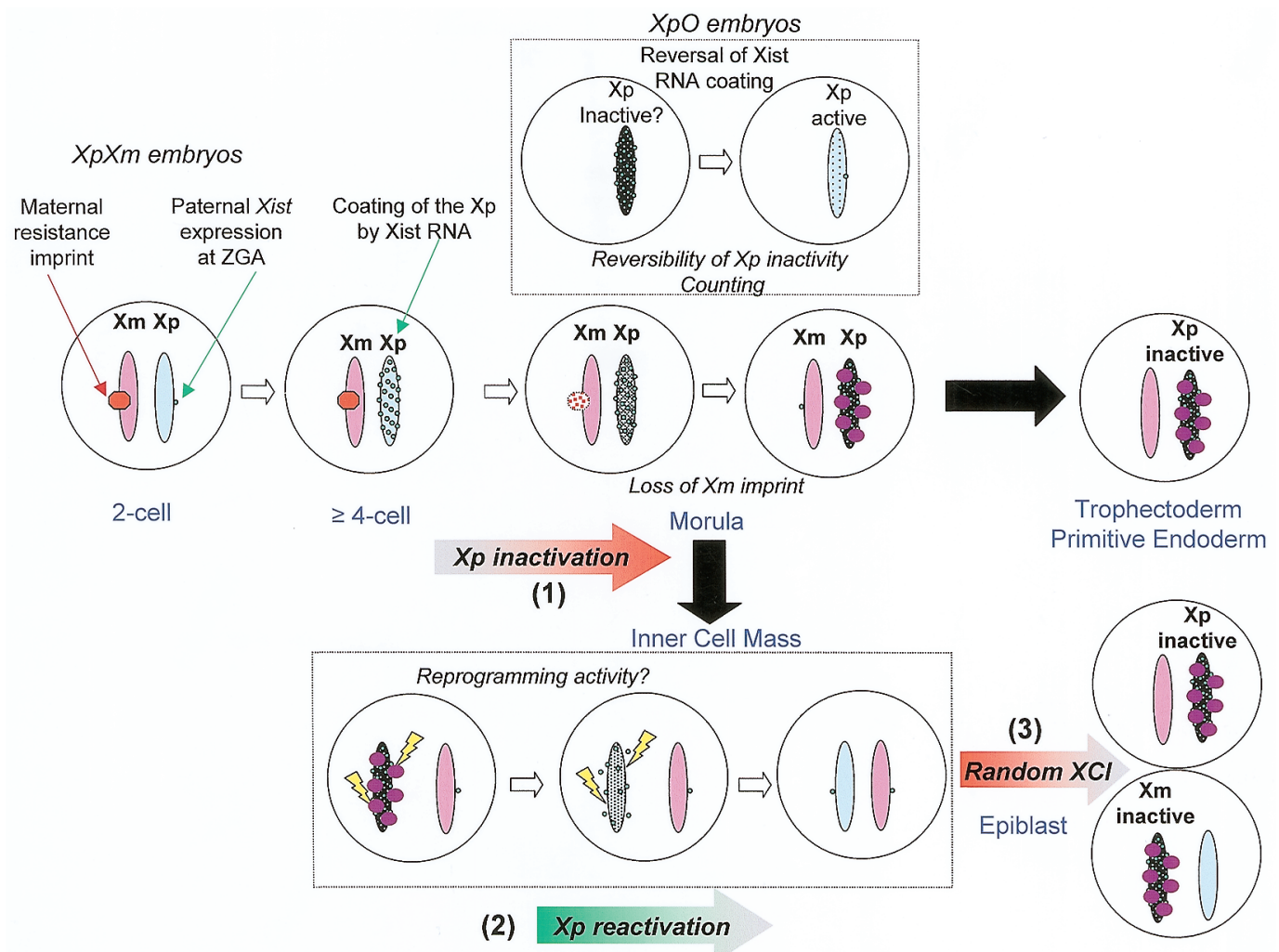

Figure 5. Proposed sequence of events underlying imprinted X-inactivation and X-reactivation in mice. (1) Initiation of Xp-inactivation: The maternal X chromosome (pink) initially carries a silent Xist gene in the zygote because of an unknown repressive imprint (red "stop" sign). The maternal imprint repressing Xist expression is lost from about the late morula to early blastocyst stage, thus the $\mathrm{Xm}$ chromosome is permissive to X-inactivation from this stage onward (see text). The Xist gene on the paternal X chromosome (blue) is switched on at zygotic gene activation (ZGA), presumably because its promoter becomes hypomethylated during spermatogenesis (Norris et al. 1994). As soon as paternal Xist RNA accumulates (green spots) and coats in cis (four-cell stage onward), it triggers transcriptional silencing (darkened chromosome). The polycomb group complex proteins Eed and Enx1 are only recruited to the Xp from the 16-cell stage or later (purple dots). By the late morula/early blastocyst stage, the $\mathrm{Xp}$ is inactive in all cells. Prior to this, there is presumably a window of time when, thanks to some form of counting, the initiation of X-inactivation can be halted or reversed if only a single $\mathrm{Xp}$ chromosome (XpO embryos, shown boxed) is present or on one of the two Xp chromosomes in androgenotes (not shown). During blastocyst growth, the Xp remains inactive and may be further locked-in by asynchronous replication timing in the trophectoderm and primitive endoderm lineages. (2) In the inner cell mass of the blastocyst the Xp is initially inactive but over the next $24 \mathrm{hr}$ or so becomes reactivated by an unknown mechanism (yellow flashes) involving loss of Xist RNA coating and expression (potentially via Tsix expression), loss of polycomb group protein association, and gradual reversal of the histone modifications. (3) Initiation of random inactivation of the Xp or Xm: Both maternal and paternal alleles of Xist are expressed at low levels, presumably very transiently, prior to the onset of random X-inactivation in the epiblast and embryo proper (see Figs. 2 and 4 for kinetics).

as a gradient from the Xist locus during early development (Latham and Rambhatla 1995; Huynh and Lee 2003). In marsupials, on the other hand, where no Xist gene has been identified, the evolution of imprinted X-inactivation may well be due to a carryover effect from the male germ line.

It will be important to determine what happens to the Xp chromosome in a female embryo where the maternal Xist allele is not imprinted to be silent. Would inactivation during early development be random in this case? This would, of course, imply that counting can occur in preimplantation embryos and there is some evidence for this from XpXp androgenotes (Okamoto et al. 2000). Alternatively, in the absence of the imprint on the Xm, would the Xp still inactivate preferentially? Just after fertilization, the protamines with which the paternal genome is packaged are replaced by histones. This dramatic remodeling may provide an opening in which the paternal genome as a whole (Aoki et al. 1997), and perhaps the paternal Xist gene in particular, are transiently more highly transcribed than their maternal counterparts, thus providing a bias toward Xist RNA transcription and accumulation on the Xp compared to the Xm. In this case, the paternal X chromosome's predisposition to inactivate would be due to its hyperactivity rather than inactivity.

\section{Kinetics of Imprinted Inactivation and Reactivation of the Paternal X Chromosome}

Up until recently, based on classic cytogenetic and biochemical studies, imprinted paternal X-inactivation in mice was believed to initiate in the first lineages to dif- 
ferentiate the trophectoderm $(3.5 \mathrm{dpc})$ and primitive endoderm $(4.5 \mathrm{dpc})$ of the blastocyst. Prior to this, the two $\mathrm{X}$ chromosomes were thought to be active, although there was some evidence that the paternal $\mathrm{X}$ chromosome displayed a lower genetic activity compared to its maternal homolog (Singer-Sam et al. 1992; Latham and Rambhatla 1995). However, because of the techniques employed, which involved protein detection (allozyme analysis, detection of LacZ and GFP reporter genes) (West et al. 1977; Tam et al. 1994a; Hadjantonakis et al. 2001) or RNA detection by reverse transcriptase polymerase chain reaction (RT-PCR) (Singer-Sam et al. 1992; Latham and Rambhatla 1995; Lebon et al. 1995), interpretation of the results could be confounded by issues such as the unknown half-lives of the X-linked transcripts and proteins examined and the fact that only pools of cells or embryos, rather than single cells, could be examined. This prompted us to develop techniques that would allow Xp silencing to be examined in single cells at the transcriptional and chromatin levels during female preimplantation development. Xp chromosome activity and the timing of imprinted $\mathrm{X}$-inactivation were investigated through the simultaneous detection of Xist RNA localization and nascent transcript detection of X-linked genes, as well as the association/depletion of RNA polymerase II (Okamoto et al. 2004; I. Okamoto and E. Heard, unpubl.). Further indicators of the inactive state came from the analysis of the PRC2 complex proteins Eed and Enx1, as well as characteristic histone modifications such as the trimethylation of Lys-27 (Plath et al. 2003) and the dimethylation of Lys-9 (Heard et al. 2001). Previous studies had shown that Xist is expressed from the two- to four-cell stage onward with exclusive expression from the paternally inherited allele only (Kay et al. 1993). Our RNA FISH and immuno-FISH analysis showed that the first signs of transcriptional inactivity of the $\mathrm{Xp}$ (exclusion of RNA PolII and down-regulation of the X-linked Chicl gene) can be detected at the four-cell stage, just after Xist RNA accumulation (Okamoto et al. 2004). The PRC2 complex and associated H3 Lys-27 methylation appear on the Xp from around the 16-cell stage (Okamoto et al. 2004), as does macroH2A (Costanzi et al. 2000), although the exact time of onset of these marks is quite variable from embyo to embryo. This variability in the time of onset of early maintenance marks could explain the ease with which the onset of Xp-inactivation can be reversed under special circumstances, such as in $\mathrm{XpO}$ embryos or XpXp androgenotes (see legend to Fig. 5). By the early blastocyst stage, however, the $\mathrm{Xp}$ is inactive in virtually all cells of normal female (XmXp) embryos. In the trophectoderm, this inactivity of the Xp is maintained, and presumably further locked in by the shift to asynchronous (early) replication timing, but what happens in the inner cell mass (ICM), which is the precursor to the embryo proper where random $\mathrm{X}$-inactivation takes place? Our laboratory and that of Neil Brockdorff demonstrated that the $\mathrm{Xp}$ is, in fact, inactive in the ICM of early blastocysts $(3.5 \mathrm{dpc})$, but during ICM growth the inactive state of the Xp is actually reversed, with cells rapidly losing their Xist RNA coating, Eed/Enx1 enrichment, and the histone modifications characteristic of $\mathrm{X}$-inactivation (Fig. 4) (Mak et al. 2004; Okamoto et al. 2004). This reactivation permits the subsequent random inactivation of either the maternal or paternal $\mathrm{X}$ chromosome in epiblast cells following implantation. Here, the cascade of events and epigenetic marks that follow are presumably similar to those found during ES cell differentiation. The activity of the Xp chromosome is thus remarkably dynamic during preimplantation development. Furthermore, these results highlight the importance of the ICM in reprogramming epigenetic marks during early embryonic development. In a previous study (Eggan et al. 2000), it was shown that in cloned mouse embryos, the inactive $\mathrm{X}$ chromosome derived from a somatic cell carried over its inactive state to the extraembryonic tissues, but was subject to random $\mathrm{X}$-inactivation in the embryo proper, presumably through the more recently uncovered reprogramming events in the ICM (Mak et al. 2004; Okamoto et al. 2004). Thus, ICM reprogramming of the $\mathrm{X}$ chromosome could have important general implications for cloning, where correct genome-wide erasure of epigenetic marks is critical for the establishment of a normal pattern of development. It will be interesting to investigate whether increasing the time span of the ICM (e.g., in diapause embryos) correlates positively with the efficiency of reprogramming and normal development in cloned embryos.

\section{Reprogramming the Inactive X Chromosome}

During female mouse embryogenesis, there are thus at least two rounds of $\mathrm{X}$-inactivation followed by reactivation (see Fig. 5). First paternal X-inactivation occurs, followed by its reactivation in the inner cell mass; next random X-inactivation occurs in the epiblast, but a few days later, in the female germ line, the inactive $\mathrm{X}$ chromosome is reactivated. Epigenetic marks, such as histone modifications and polycomb group proteins, that ensure the cellular memory of the inactive state early on in development can be rapidly removed in the ICM. Loss of Xist RNA coating and Xist down-regulation appear to be accompanied by dissociation of the polycomb proteins from the Xp in this process and precede the loss of H3 Lys-27 and Lys-9 methylation (Mak et al. 2004; Okamoto et al. 2004) and the reactivation of X-linked genes (I. Okamoto and E. Heard, unpubl.). How Xist RNA becomes downregulated on the $\mathrm{Xp}$ chromosome thus appears to be the critical question for understanding Xp-reactivation in the ICM. Given that Tsix is expressed at around this time and the repressive effect it has on Xist expression, this may be when Tsix actually plays a critical role in vivo.

DNA methylation of $\mathrm{CpG}$ islands of X-linked genes only occurs after the second wave of (random) X-inactivation. This mark is therefore present on the $\mathrm{Xi}$, both in the soma and in the female germ line. How epigenetic marks, including DNA methylation, are reversed on the $\mathrm{Xi}$ in the germ line remains unknown. Both specific processes and common mechanisms that erase imprints and reprogram other loci are likely to be involved. Kinetic studies suggest that Xist RNA delocalization and macroH2A dissociation 
occur at $11.5 \mathrm{dpc}$ during Xi-reactivation (Nesterova et al. 2002), when migrating germ cells enter the genital ridge (Tam et al. 1994). The exact relative timing of events requires further investigation.

Insights into the mechanisms and factors involved in the reactivation of the $\mathrm{X}$ chromosome should come from studies involving tissue-culture derivatives of the ICM and germ cells, namely ES and EG (embryonic germ) cells, respectively. Global reactivation of the Xi has been reported following fusion of female somatic cells with ES, embryonal carcinoma (EC), or EG cells (Yoshida et al. 1997; Tada et al. 2001). In one study, a minimum of five mitoses was required to reactivate the $\mathrm{Xi}$ at the level of replication timing, following fusion between a female thymocyte and an EC cell (Takagi 1988). This is consistent with the requirement of several rounds of DNA replication for the reversal of stable epigenetic marks such as DNA methylation (in the absence of any known DNA demethylases) and contrasts with the more rapid reversal of Xp-inactivity seen in the ICM, where no DNA methylation or asynchronous replication is present. Whether common reprogramming mechanisms are involved in reactivating the inactive $\mathrm{X}$ chromosome in the ICM and the germ line and the nature of the factors that are involved are exciting questions for future investigation.

\section{X-INACTIVATION IN THE CONTEXT OF NUCLEAR ORGANIZATION}

It is increasingly recognized that the localization of genes within specific nuclear compartments can be an important means of regulating gene expression (Cockell and Gasser 1999; Spector 2003). Subnuclear domains enriched in factors specialized in particular functions may provide a nuclear context, beyond that provided by flanking sequences, that influences chromatin architecture and gene expression. One of the most intriguing features of the X-inactivation process is the differential treatment of two identical chromosomes within the same nucleoplasm. How does one $\mathrm{X}$ chromosome become impervious to the same transcriptional machinery driving genetic activity of the second X chromosome? Spatial segregation of the two $\mathrm{X}$ chromosomes could be imagined to play a role both in the establishment and in the maintenance of $\mathrm{X}$-inactivation. At the level of initiation, nuclear compartmentalization mediated by binding of one X chromosome to a single entity per nucleus was one of the earliest models proposed to explain the differential treatment of the two X chromosomes during X-inactivation (Comings 1968). In this context, one hypothesis for "counting" could be that the Xic on the X chromosome that will remain active is sequestered in a particular nuclear region, preventing it from exposure to factors involved in triggering X-inactivation. Transient colocalization or cross talk between Xics, as reported for imprinted loci (LaSalle and Lalande 1996), might also help the cell to count or "sense" the number of X chromosomes present (Fig. 6A). This hypothesis is particularly attractive in the light of the incapacity of single-copy transgenes to function as ec- topic Xics and, more specifically, their inability to induce counting. An absence of long-range elements involved in directing the correct nuclear position of the Xic could result in these transgenes not being correctly "sensed" as supernumerary Xics because of their aberrant localization in the nucleus or with respect to the other Xic (Fig. 6A). The actual region of the Xic that has to be sensed could either be the counting region $3^{\prime}$ to Xist or else the Xist gene itself, as some kind of cross talk between Xist alleles has previously been proposed to be involved in the choice of $\mathrm{X}$ chromosome to inactivate during initiation (Marahrens et al. 1998).

The epigenetic modifications underlying X-chromosome-wide silencing and its maintenance might also extend beyond the level of chromatin structure and include changes in chromosome positioning within the nucleus and/or local changes in the nuclear compartment surrounding the $\mathrm{X}$ chromosome (Fig. 6B). Indeed, our recent data, showing that the exclusion of transcriptional machinery from the $\mathrm{X}$ chromosome is the earliest event induced by Xist RNA coating, prior to changes in histone modifications (J. Chaumeil and E. Heard, in prep.), could be consistent with this. Xist RNA coating may create a nuclear subcompartment depleted in members of the gene expression machinery. Transcriptional silencing of the $\mathrm{X}$ chromosome may thus initially be induced by exclusion of the transcription apparatus rather than by recruitment of repressors, although the two mechanisms are clearly not mutually exclusive.

To date, few studies have examined the role of nuclear compartmentalization in $\mathrm{X}$-inactivation largely because of technical limitations. The recent advent of new technology such as the $3 \mathrm{C}$ technique (Dekker et al. 2002; Tolhuis et al. 2002) and of fluorescently tagged markers should open up the way to in vivo visualization and analysis of the spatial organization of the Xic and the Xist transcript and should enable the dynamic subnuclear localization of these key players in the $\mathrm{X}$-inactivation process to be unraveled.

\section{CONCLUSIONS}

We have attempted to cover various aspects of X-chromosome inactivation, putting emphasis on those features of the process that may be relevant to other epigenetic phenomena and raising some of the numerous issues that we feel have not yet been fully addressed to date. The nature and extent of the Xic region that ensures the correct $\mathrm{X}$-inactivation remains an outstanding question, the answer to which, we feel, may lie in the as yet unexplored dimension of nuclear organization. The nature of Xist RNA's silencing role is also a tantalizing issue, which will hopefully be resolved in the near future thanks to elegant studies dissecting function of different regions of this transcript (Wutz et al. 2002) and may also implicate nuclear segregation in addition to chromatin changes. The chromatin-modifying complexes involved in setting up the stability and mitotic heritability of the inactive $\mathrm{X}$ chromosome will no doubt be rapidly deciphered thanks 


\section{A. INITIATION : Regulation of counting and choice by nuclear localization}

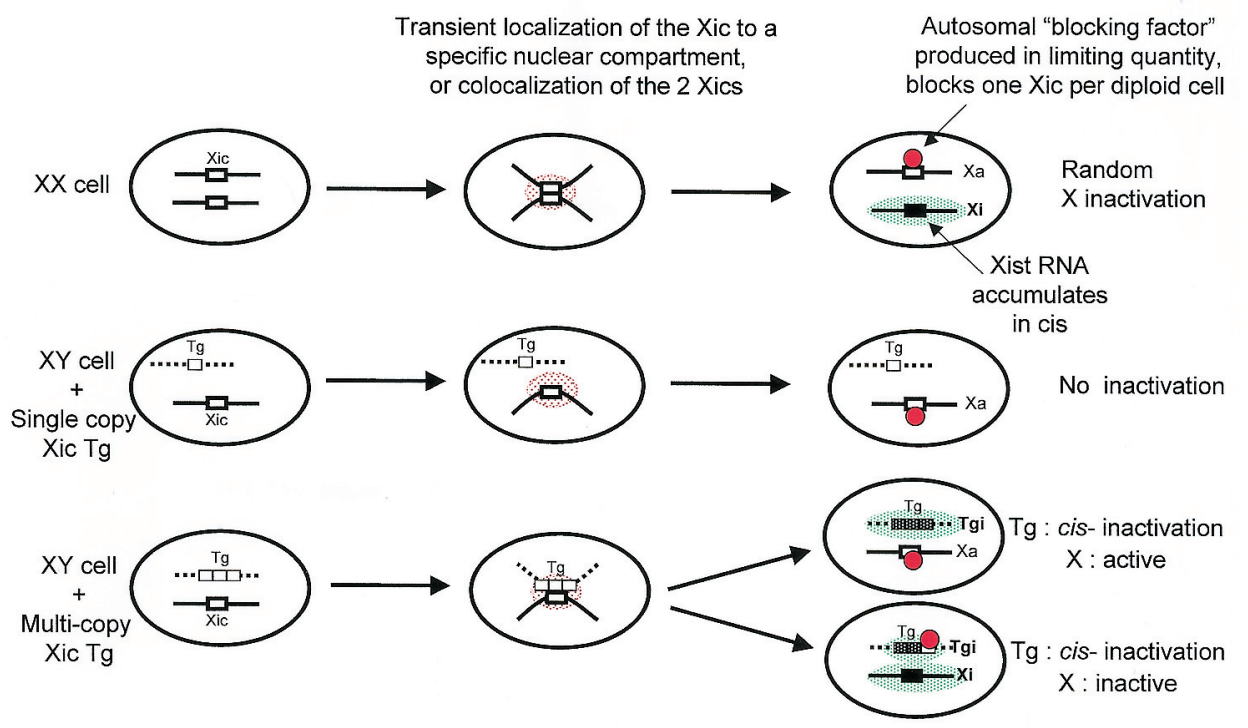

B. XIST RNA MEDIATED SILENCING

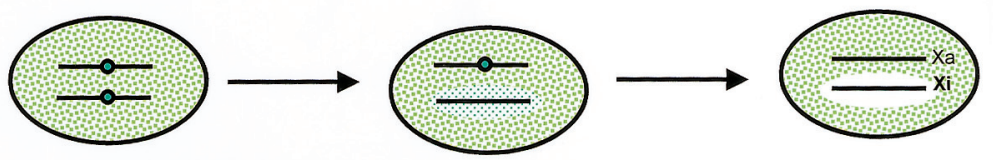

Xist RNA excludes transcription complexes, or sequesters the inactive $\mathrm{X}$ to a "silencing" compartment

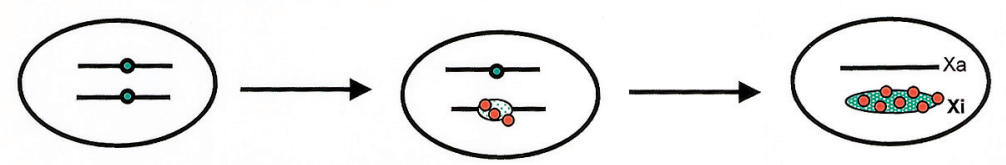

Xist RNA recruits silencing complexes and creates a "silent" compartment

Figure 6. Possible roles for nuclear compartmentalization during X-inactivation. $(A)$ Nuclear localization during the initiation phase of X-inactivation: Models for counting usually evoke the action of an autosomally encoded blocking factor, produced in limited quantity, that binds a single Xic (per diploid autosome set) and prevents it from initiating X-inactivation. Transient localization of all of the Xics in a cell (XX cell shown, top row) within a compartment enriched in this limiting blocking factor (red spots), or even transient physical interaction between the Xics, may be required to count or sense the number of Xics present and ensure that only one will remain active per diploid cell. The active X has no Xist RNA accumulation and its Xic is blocked (red circle) within the counting region 3' to Xist (see Fig. 1). All other Xics are free to accumulate Xist RNA and trigger inactivation in cis. In XY cells with a single-copy Xic transgene, however, the elements required to position the transgene in the correct nuclear location, or to interact with the Xic on the X chromosome, may be lacking and the transgene is not sensed as a second Xic and cannot trigger the counting process. Multiple copies of transgenes in a tandem array (but not at independent locations; see Heard et al. 1999) can override this lack of single-copy function and compensate for the missing elements. The latter are likely to lie in the $5^{\prime}$ region of Xist (see text for details). (B) Nuclear segregation during the propagation and maintenance phases of X-inactivation: Our recent data (J. Chaumeil and E. Heard, unpubl.) suggest that Xist RNA may trigger transcriptional silencing by excluding or impeding transcription factors (top). Alternatively, Xist RNA could act by recruiting silencing factors (bottom). These are not mutually exclusive possibilities (see text for details). Spatial and temporal segregation of the Xi relative to the active X chromosome and other active regions of the genome could then also participate in the highly efficient maintenance of the inactive state, once it has been established, throughout the cell cycle.

to the work of biochemists. The evolutionary origins of imprinted $\mathrm{X}$-inactivation may be less easy to solve, given the complexity of the selective pressures that are likely to act on X-inactivation during early development, although clearly studies investigating the early events and players in X-inactivation in species other than mouse will be important to address this issue. Finally, the reprogramming events that the inactive $\mathrm{X}$ chromosome is subject to during development should provide us with important insights into the factors underlying the nature of stem cells and the mechanisms involved in cloning during the reprogramming of the genome.

\section{ACKNOWLEDGMENTS}

The authors wish to apologize for any omissions in references that may have been made and would like to thank Vincent Colot for critical input on the manuscript, as well as Géneviève Almouzni for her helpful comments. The work by our group described in this review was funded by 
the CNRS (ATIPE), the Human Frontier Science Program, the French Ministry of Research (ACI), and the Curie Institute (Program Incitatif et Collaboratif).

\section{REFERENCES}

Angelov D., Molla A., Perche P.Y., Hans F., Cote J., Khochbin S., Bouvet P., and Dimitrov S. 2003. The histone variant macroH2A interferes with transcription factor binding and SWI/SNF nucleosome remodeling. Mol. Cell 11: 1033.

Aoki F., Worrard D.M., and Schultz R. 1997. Regulation of transcriptional activity during the first and second cell cycles in the preimplantation mouse embryos. Dev. Biol. 181: 296.

Ariel M., Robinson E., McCarrey J.R., and Cedar H. 1995. Gamete-specific methylation correlates with imprinting of the murine Xist gene. Nat. Genet. 9: 312.

Boggs B.A., Connors B., Sobel R.E., Chinault A.C., and Allis C.D. 1996. Reduced levels of histone H3 acetylation on the inactive $\mathrm{X}$ chromosome in human females. Chromosoma 105: 303.

Boggs B.A., Cheung P., Heard E., Spector D.L., Chinault C.A., and Allis C.D. 2002. Differentially methylated forms of histone $\mathrm{H} 3$ show unique association patterns with inactive human X chromosomes. Nat. Genet. 30: 73.

Boumil R.M. and Lee J. 2001. Forty years of decoding the silence in X-chromosome inactivation. Hum. Mol. Genet. 10: 2225.

Brown C.J., Ballabio A., Rupert J.L., Lafreniere R.G., Grompe M., Tonlorenzi R., and Willard H.F. 1991. A gene from the region of the human $\mathrm{X}$ inactivation centre is expressed exclusively from the inactive X chromosome. Nature 349: 38.

Brown C.J., Hendrich B.D., Rupert J.L., Lafreniere R.G., Xing Y., Lawrence J., and Willard H.F. 1992. The human XIST gene: Analysis of a $17 \mathrm{~kb}$ inactive X-specific RNA that contains conserved repeats and is highly localized within the nucleus. Cell 71: 527.

Burgoyne P.S. and Biggers J.D. 1976. The consequences of Xdosage deficiency in the germ line: Impaired development in vitro of preimplantation embryos from X0 mice. Dev. Biol. 51: 109.

Cao R. and Zhang Y. 2004. The functions of E(Z)/EZH2-mediated methylation of lysine 27 in histone H3. Curr. Opin. Genet. Dev. 14: 155.

Chadwick B. and Willard H.F. 2003. Chromatin of the Barr body: Histone and non-histone proteins associated with or excluded from the inactive X chromosome. Human Mol. Genet. 12: 2167.

Chaumeil J., Okamoto I., Guggiari M., and Heard E. 2002. Integrated kinetics of $\mathrm{X}$ chromosome inactivation in differentiating embryonic stem cells. Cytogenet. Cell Genet. 99: 75.

Chureau C., Prissette M., Bourdet A., Barbe V., Cattolico L., Jones L., Eggen A., Avner P., and Duret L. 2002. Comparative sequence analysis of the $\mathrm{X}$-inactivation center region in mouse, human, and bovine. Genome Res. 12: 894.

Clemson C.M., Chow J.C., Brown C.J., and Lawrence J.B. 1998. Stabilization and localization of Xist RNA are controlled by separate mechanisms and are not sufficient for X inactivation. J. Cell Biol. 142: 13.

Clerc P. and Avner P. 1998. Role of the region 3' to Xist exon 6 in the counting process of X-chromosome inactivation. Nat. Genet. 19: 249.

. 2003. Multiple elements within the Xic regulate random $\mathrm{X}$ inactivation in mice. Semin. Cell Dev. Biol. 14: 85.

Cockell M. and Gasser S. 1999. Nuclear compartments and gene regulation. Curr. Opin. Genet. Dev. 9: 199.

Comings D.E. 1968. The rationale for an ordered arrangement of chromatin in the interphase nucleus. Am. J. Hum. Genet. 20: 440.

Cooper D.W., VandeBerg J.L., Sharman G.B., and Poole W.E. 1971. Phosphoglycerate linase polymorphism in kangaroos provides further evidence for paternal X inactivation. Nat. New Biol. 230: 155.

Costanzi C. and Pehrson J.R. 1998. Histone macroH2A.1 is con- centrated on the inactive $\mathrm{X}$ chromosome of female mammals. Nature 393: 599.

Costanzi C., Stein P., Worrad D.M., Schultz R.M., and Pehrson J.R. 2000. Histone macroH2A1 is concentrated in the inactive $\mathrm{X}$ chromosome of female preimplantation mouse embryos. Development 127: 2283.

Csankovszki G., Nagy A., and Jaenisch R. 2001. Synergism of Xist RNA, DNA methylation, and histone hypoacetylation in maintaining X chromosome inactivation. J. Cell Biol. 153: 773.

Csankovszki G., Panning B., Bates B., Pehrson J.R., and Jaenisch R. 1999. Conditional deletion of Xist disrupts histone macroH2A localization but not maintenance of X inactivation. Nat. Genet. 22: 323.

Debrand E., Chureau C., Arnaud D., Avner P., and Heard E. 1999. Functional analysis of the DXPas 34 locus: A 3' regulator of Xist expression. Mol. Cell. Biol. 19: 8513.

Dekker J., Rippe K., Dekker M., and Kleckner N. 2002. Capturing chromosome conformation. Science 295: 1306.

Eggan K., Akutsu H., Hochedlinger K., Rideout W., III, Yanagimachi R., and Jaenisch R. 2000. X-chromosome inactivation in cloned mouse embryos. Science 290: 1578.

Fernandez-Capetillo O., Mahadevaiah S.K., Celeste A., Romanienko P.J., Camerini-Otero R.D., Bonner W.M., Manova K., Burgoyne P., and Nussenzweig A. 2003. H2AX is required for chromatin remodeling and inactivation of sex chromosomes in male mouse meiosis. Dev. Cell. 4: 497.

Fischle W., Wang Y., Jacobs S.A., Kim Y., Allis C.D., and Khorasanizadeh S. 2003. Molecular basis for the discrimination of repressive methyl-lysine marks in histone $\mathrm{H} 3$ by Polycomb and HP1 chromodomains. Genes Dev. 17: 1870.

Goto T. and Monk M. 1998. The regulation of X-chromosome inactivation in development in mouse and human. Microbiol. Mol. Biol. Rev. 62: 362.

Goto Y. and Takagi N. 1998. Tetraploid embryos rescue embryonic lethality caused by an additional maternally inherited X chromosome in the mouse. Development 125: 3353.

1999. Maternally inherted X chromosome is not inactivated in mouse blastocysts due to parental imprinting. Chromosome Res. 7: 101.

Graves J.A. and Westerman M. 2002. Marsupial genetics and genomics. Trends Genet. 18: 517.

Hadjantonakis A.K., Cox L.L., Tam P.P., and Nagy A. 2001. An $\mathrm{X}$-linked GFP transgene reveals unexpected paternal X-chromosome activity in trophoblastic giant cells of the mouse placenta. Genesis 29: 133.

Heard E. and Avner P. 1994. Role play in X-inactivation. Hum. Mol. Genet. 3: 1481.

Heard E., Clerc P., and Avner P. 1997. X chromosome inactivation in mammals. Annu. Rev. Genet. 31: 571.

Heard E., Mongelard F., Arnaud D., and Avner P. 1999. Xist YAC transgenes function as Xics only in multicopy arrays and not as single copies. Mol. Cell. Biol. 19: 3156.

Heard E., Rougeulle C., Arnaud D., Avner P., Allis C.D., and Spector D.L. 2001. Methylation of histone H3 at Lys-9 is an early mark on the X chromosome during X-inactivation. Cell 107: 727.

Heard E., Kress C., Mongelard F., Courtier B., Rougeulle C., Ashworth A., Vourc'h C., Babinet C., and Avner P. 1996. Transgenic mice carrying an Xist-containing YAC. Hum. Mol. Genet. 5: 441.

Hendriksen P.J., Hoogerbrugge J.W., Themmen A.P., Koken M.H., Hoeijmakers J.H., Oostra B.A., van der Lende T., and Grootegoed J.A. 1995. Postmeiotic transcription of X and Y chromosomal genes during spermatogenesis in the mouse. Dev. Biol. 170: 730 .

Henikoff S., Furuyama T., and Ahmad K. 2004. Histone variants, nucleosome assembly and epigenetic inheritance. Trends Genet. 20: 320.

Herzing L.B., Romer J.T., Horn J.M., and Ashworth A. 1997. Xist has properties of the X-chromosome inactivation centre. Nature 386: 272.

Huynh K.D. and Lee J.T. 2000. Imprinted X inactivation in eutherians: A model of gametic execution and zygotic relation. 
Curr. Opin. Cell Biol. 13: 690

Huynh K.D. and Lee J.T. 2003. Inheritance of a pre-inactivated paternal X chromosome in early mouse embryos. Nature $\mathbf{4 2 6}$ : 857.

Jablonka E. and Lamb M.J. 1988. Meiotic pairing constraints and the activity of sex chromosomes. J. Theor. Biol. 133: 23.

Jamieson R.V., Tam P.P.L., and Gardiner-Garden M. 1997. Xchromosome activity: Impact of imprinting and chromatin structure. Int. J. Dev. Biol. 40: 1065.

Jenuwein T. and Allis C.D. 2001. Translating the histone code. Science 293: 1074.

Jeppesen P. and Turner B.M. 1993. The inactive X chromosome in female mammals is distinguished by a lack of histone H4 acetylation, a cytogenetic marker for gene expression. Cell 74: 281.

Kaslow D.C. and Migeon B.R. 1987. DNA methylation stabilizes $\mathrm{X}$ chromosome inactivation in eutherians but not in marsupials: Evidence for multistep maintenance of mammalian X dosage compensation. Proc. Natl. Acad. Sci. 84: 6210.

Kay G.F., Barton S.C., Surani M.A., and Rastan S. 1994. Imprinting and $\mathrm{X}$ chromosome counting mechanisms determine Xist expression in early mouse development. Cell 77: 639.

Kay G.F., Penny G.D., Patel D., Ashworth A., Brockdorff N., and Rastan S. 1993. Expression of Xist during mouse development suggests a role in the initiation of X chromosome inactivation. Cell 72: 171.

Keohane A.M., O’Neill L.P., Belyaev N.D., Lavender J.S., and Turner B.M. 1996. X inactivation and histone H4 acetylation in ES cells. Dev. Biol. 180: 618.

Kohlmaier A., Savarese F., Lachner M., Martens J., Jenuwein T., and Wutz A. 2004. A chromosomal memory triggered by xist regulates histone methylation in $\mathrm{x}$ inactivation. PLoS Biol. 2: E171.

Kratzer P.G., Chapman V.M., Lambert H., Evans R.E., and Liskay R.M. 1983. Differences in the DNA of the inactive X chromosome of fetal and extraembryonic tissues of mice. Cell 33: 37 .

Kuzmichev A., Nishioka K., Erdjumant-Bromage H., Tempst P., and Reinberg D. 2002. Histone methyltransferase activity associated with a human multiprotein complex containing the Enhancer of Zeste protein. Genes Dev. 16: 2893

LaSalle J.M. and Lalande M. 1996. Homologous association of oppositely imprinted chromosomal domains. Science 272: 725.

Latham K.E. and Rambhatla L. 1995. Expression of X-linked genes in androgenetic, cytogenetic and normal mouse preimplantation embryos. Dev. Genet. 17: 212.

Lebon J.M., Tam P.P., Singer-Sam J., Riggs A.D., and Tan S.S. 1995. Mouse endogenous X-linked genes do not show lineage-specific delayed inactivation during development. Genet. Res. 65: 223.

Lee J.T. 2000. Disruption of imprinted X inactivation by parentof-origin effects at Tsix. Cell 103: 17.

Lee J.T., Davidow L.S., and Warshawsky D. 1999a. Tsix, a gene antisense to Xist at the X-inactivation centre. Nat. Genet. 21: 400.

Lee J.T., Lu N., and Han Y. 1999b. Genetic analysis of the mouse $\mathrm{X}$ inactivation center defines an $80-\mathrm{kb}$ multifunction domain. Proc. Natl. Acad. Sci. 96: 3836.

Lee J.T., Strauss W.M., Dausman J.A., and Jaenisch R. 1996. A $450 \mathrm{~kb}$ transgene displays properties of the mammalian X-inactivation center. Cell 86: 83.

Lifschytz E. and Lindsley D.L. 1972. The role of X-chromosome inactivation during spermatogenesis (Drosophila-allocyclychromosome evolution-male sterility-dosage compensation). Proc. Natl. Acad. Sci. 69: 182.

Lyon M.F. 1961. Gene action in the X chromosome of the mouse (Mus musculus L.). Nature 190: 372.

1998. X-chromosome inactivation: A repeat hypothesis. Cytogenet. Cell Genet. 80: 133.

Lyon M.F. and Rastan S. 1984. Parental source of chromosome imprinting and its relevance for $\mathrm{X}$ chromosome inactivation. Differentiation 26: 63.

Mak W., Nesterova T.B., de Napoles M., Appanah R., Ya- manaka S., Otte A.P., and Brockdorff N. 2004. Reactivation of the paternal X chromosome in early mouse embryos. Science 303: 666.

Marahrens Y., Loring J., and Jaenisch R. 1998. Role of the Xist gene in X chromosome choosing. Cell 92: 657.

Marahrens Y., Panning B., Dausman J., Strauss W., and Jaenisch R. 1997. Xist-deficient mice are defective in dosage compensation but not spermatogenesis. Genes Dev. 11: 156.

McCarrey J.R., Watson C., Atencio J., Ostermeier G.C., Marahrens Y., Jaenisch R., and Krawetz S.A. 2002. X-chromosome inactivation during spermatogenesis is regulated by an Xist/Tsix-independent mechanism in the mouse. Genesis 34: 257.

McDonald L.E., Paterson C.A., and Kay G.F. 1998. Bisulfite genomic sequencing-derived methylation profile of the Xist gene throughout early mouse development. Genomics. 54: 379.

Min J., Zhang Y., and Xu R.M. 2003. Structural basis for specific binding of Polycomb chromodomain to histone $\mathrm{H} 3$ methylated at Lys 27. Genes Dev. 17: 1823.

Nesterova T.B., Mermoud J.E., Brockdorff N., Hilton K., McLaren A., Surani M.A., and Pehrson J. 2002. Xist expression and macroH2A1.2 localisation in mouse primordial and pluripotent embryonic germ cells. Differentiation 69: 216 .

Norris D.P., Patel D., Kay G.F., Penny G.D., Brockdorff N., Sheardown S.A., and Rastan S. 1994. Evidence that random and imprinted Xist expression is controlled by preemptive methylation. Cell 77: 41.

Ohlsson R., Paldi A., and Graves J.A. 2001. Did genomic imprinting and $\mathrm{X}$ chromosome inactivation arise from stochastic expression? Trends Genet. 17: 136.

Okamoto I., Tan S., and Takagi N. 2000. X-chromosome inactivation in $\mathrm{XX}$ androgenetic mouse embryos surviving transplantation. Development 127: 4137.

Okamoto I., Otte A.P., Allis C.D., Reinberg D., and Heard E. 2004. Epigenetic dynamics of imprinted X inactivation during early mouse development. Science 303: 644.

O’Neill L.P., Keohane A.M., Levender J.S., McCabe V., Heard E., Avner P., Brockdorff N., and Turner B.M. 1999. A developmental switch in $\mathrm{H} 4$ acetylation upstream of Xist plays a role in X chromosome inactivation. EMBO J. 18: 2897.

Panning B., Dausman J., and Jaenisch R. 1997. X-chromosome inactivation is mediated by Xist RNA stabilisation. Cell 90: 907.

Penny G.D., Kay G.F., Sheardown S.S., Rastan S., and Brockdorff N. 1996. Requirement for Xist in X chromosome inactivation. Nature 379: 131.

Plath K., Fang J., Mlynarczyk-Evans S.K., Cao R., Worringer K.A., Wang H., de la Cruz C.C., Otte A.P., Panning B., and Zhang Y. 2003. Role of histone H3 lysine 27 methylation in $\mathrm{X}$ inactivation. Science 300: 131.

Prissette M., El-Marrii O., Arnaud D., Walter J., and Avner P. 2001. Methylation profiles of DXPas 34 during the onset of X inactivation. Hum. Mol. Genet. 10: 31.

Rastan S. 1983. Non-random X-chromosome inactivation in mouse $\mathrm{X}$-autosome translocation embryos: Location of the inactivation centre. J. Embryol. Exp. Morphol. 78: 1.

Rastan S. and Robertson E.J. 1985. X chromosome deletions in embryo-derived EK cell lines associated with lack of X chromosome inactivation. J. Embryol. Exp. Morphol. 90: 379.

Richardson B.J., Czuppon A.B., and Sharman G.B. 1971. Inheritance of glucose-6-phosphate dehydrogenase variation in kangaroos. Nat. New Biol. 230: 154.

Riggs A.D., Singer S.J., and Keith D.H. 1985. Methylation of the PGK promoter region and an enhancer waystation model for $\mathrm{X}$ chromosome inactivation. In Biochemistry and biology of DNA methylation (ed. G.L. Cantoni and A. Razin), p. 211. Alan R. Liss, New York.

Rougeulle C., Chaumeil J., Sarma K., Allis C.D., Reinberg D., Avner P., and Heard E. 2004. Differential histone H3 Lys-9 and Lys-27 methylation profiles on the X chromosome. Mol. Cell. Biol. 24: 5475.

Sado T., Wang Z., Sasaki H., and Li E. 2001. Regulation of imprinted X-chromosome inactivation in mice by Tsix. Devel- 
opment 128: 1275.

Sado T., Fenner M.H., Tan S.S., Tam P., Shioda T., and Li E. 2000. X inactivation in the mouse embryo deficient for Dnmt1: Distinct effect of hypomethylation on imprinted and random X inactivation. Dev. Biol. 225: 294.

Selwood L. 2001. Mechanisms for pattern formation leading to axis formation and lineage allocation in mammals: A marsupial perspective. Reproduction 121: 677.

Sharman G.B. 1971. Late DNA replication in the paternally derived X chromosome of female kangaroos. Nature 230: 231.

Sheardown S.A., Duthie S.M., Johnston C.M., Newall A.E., Formstone E.J., Arkell R.M., Nesterova T.B., Alghisi G.C., Rastan S., and Brockdorff N. 1997. Stabilization of Xist RNA mediates initiation of X chromosome inactivation. Cell 91: 99.

Silva J., Mak W., Zvetkova I., Appanah R., Nesterova T.B., Webster Z., Peters A.H., Jenuwein T., Otte A.P., and Brockdorff N. 2003. Establishment of histone h3 methylation on the inactive $\mathrm{X}$ chromosome requires transient recruitment of EedEnx1 polycomb group complexes. Dev. Cell 4: 481.

Singer-Sam J., Chapman V., Lebon J.M., and Riggs A.D. 1992. Parental imprinting studied by allele-specific primer extension after PCR: Paternal X chromosome-linked genes are transcribed prior to preferential paternal X chromosome inactivation. Proc. Natl. Acad. Sci. 89: 10469.

Spector D. 2003. The dynamics of chromosome organization and gene regulation. Annu. Rev. Biochem. 72: 573.

Stavropoulos N., Lu N., and Lee J.T. 2001. A functional role for Tsix transcription in blocking Xist RNA accumulation but not in X-chromosome choice. Proc. Natl. Acad. Sci. 98: 10232.

Strahl B.D. and Allis C.D. 2000. The language of covalent histone modifications. Nature 403: 41.

Tada M., Takahama Y., Abe K., Nakatsuji N., and Tada T. 2001. Nuclear reprogramming of somatic cells by in vitro hybridization with ES cells. Curr. Biol. 11: 1553.

Tada T., Obata Y., Tada M., Goto Y., Nakatsuji N., Tan S., Kono T., and Takagi N. 2000. Imprint switching for non-random Xchromosome inactivation during mouse oocyte growth. Development 127: 3101.

Tajul-Arifin K., Teasdale R., Ravasi T., Hume D.A., Mattick J.S., RIKEN GER Group, and GSL Members. 2003. Identification and analysis of chromodomain-containing proteins encoded in the mouse transcriptome. Genome Res. 13: 1416

Takagi N. 1988. Requirement of mitoses for the reversal of Xinactivation in cell hybrids between murine embryonal carcinoma cells and normal female thymocytes. Exp. Cell Res. 175: 363 .

Takagi N. and Sasaki M. 1975. Preferential inactivation of the paternally derived $\mathrm{X}$ chromosome in the extraembryonic membranes of the mouse. Nature 256: 640.

Tam P.P., Williams E.A., and Tan S.S. 1994a. Expression of an $\mathrm{X}$-linked HMG-lacZ transgene in mouse embryos: Implication of chromosomal imprinting and lineage specific X-chromosome activity. Dev. Genet. 15: 491.

Tam P.P., Zhou S.X., and Tan S.S. 1994b. X-chromosome activity of the mouse primordial germ cells revealed by the expression of an X-linked lacZ transgene. Development 120: 2925.

Tolhuis B., Palstra R.J., Splinter E., Grosveld F., and de Laat W. 2002. Looping and interaction between hypersensitive sites in the active $\beta$-globin locus. Mol. Cell 10: 1453.

Turner B.M. 2000. Histone acetylation and an epigenetic code. Bioessays 22: 836.

Turner J.M., Mahadevaiah S.K., Elliott D.J., Garchon H.J., Pehrson J.R., Jaenisch R., and Burgoyne P.S. 2002. Meiotic sex chromosome inactivation in male mice with targeted disruptions of Xist. J. Cell Sci. 115: 4097.

Wang J., Mager J., Chen Y., Schneider E., Cross J.C., Nagy A., and Magnuson T. 2001. Imprinted X inactivation maintained by a mouse Polycomb group gene. Nat. Genet. 28: 371 .

Watson C.M., Hughes R.L., Cooper D.W., Gemmell R.T., Loebel D.A., and Johnston P.G. 2000. Sexual development in marsupials: Genetic characterization of bandicoot siblings with scrotal and testicular maldevelopment. Mol. Reprod. Dev. 57: 127.

West J.D., Frels W.I., Chapman V.M., and Papaioannou V.E. 1977. Preferential expression of the maternally derived X chromosome in the mouse yolk sac. Cell 12: 873 .

Wutz A. and Jaenisch R. 2000. A shift from reversible to irreversible $\mathrm{X}$ inactivation is triggered during ES cell differentiation. Mol. Cell 5: 695.

Wutz A., Rasmussen T.P., and Jaenisch R. 2002. Chromosomal silencing and localization are mediated by different domains of Xist RNA. Nat. Genet. 30: 167.

Xue F., Tian X.C., Du F., Kubota C., Taneja M., Dinnyes A., Dai Y., Levine H., Pereira L.V., and Yang X. 2002. Aberrant patterns of X chromosome inactivation in bovine clones. Nat. Genet. 31: 216.

Yoshida I., Nishita Y., Mohandas T.K., and Takagi N. 1997. Reactivation of an inactive human $\mathrm{X}$ chromosome introduced into mouse embryonal carcinoma cells by microcell fusion with persistent expression of XIST. Exp. Cell Res. 230: 208.

Zhang Y. and Reinberg D. 2001. Transcription regulation by histone methylation: Interplay between different covalent modifications of the core histone tails. Genes Dev. 15: 2343.

Zuccotti M. and Monk M. 1995. Methylation of the mouse Xist gene in sperm and eggs correlates with imprinted Xist expression and paternal X-inactivation. Nat. Genet. 9: 316. 


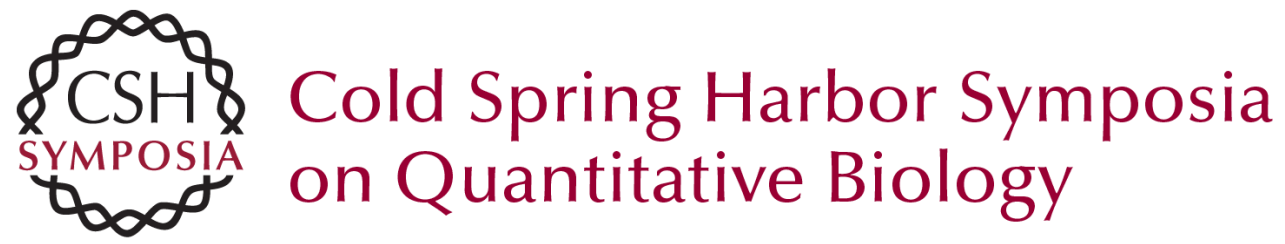

\section{Mammalian X-Chromosome Inactivation: An Epigenetics Paradigm}

E. HEARD, J. CHAUMEIL, O. MASUI, et al.

Cold Spring Harb Symp Quant Biol 2004 69: 89-102

Access the most recent version at doi:10.1101/sqb.2004.69.89

References This article cites 114 articles, 34 of which can be accessed free at: http://symposium.cshlp.org/content/69/89.full.html\#ref-list-1

\section{License}

Email Alerting

Receive free email alerts when new articles cite this article - sign up in Service the box at the top right corner of the article or click here. 